\title{
As condições do estudo sociológico dos linchamentos no Brasil
}

\author{
JOSÉ DE SOUZA MARTINS
}

$\mathrm{O}$ S LINCHAMENTOS VÊM ganhando notoriedade no Brasil nos últimos vinte anos. Eles têm ocorrido mais ou menos paralelamente a outras duas formas de comportamento coletivo: os saques e os quebra-quebras. $\mathrm{Na}$ verdade, os linchamentos não são uma novidade na sociedade brasileira. Há registros documentais de formas de justiçamento desse tipo no país já na primeira metade do século XVIII, antes mesmo que aparecesse a palavra que o designa. Os jornais brasileiros do final do século XIX, aproximadamente a partir das vésperas da abolição da escravatura negra, trazem freqüentes notícias de linchamentos nos Estados Unidos, mas também, no Brasil. Eram linchamentos de motivação racial, contra negros, mas também contra seus protetores brancos. Nessa época, a palavra linchamento já era de uso corrente no vocabulário brasileiro.

É significativo que as três formas de protesto popular citadas tenham despertado menos a atenção dos cientistas sociais brasileiros do que os movimentos sociais organizados. Não é demais lembrar que a elaboração teórica do comportamento coletivo antecedeu a formulação do conceito (e das teorias) de movimento social. Cada uma dessas formas de protesto, porém, motivou um número muito reduzido de estudos sociológicos e antropológicos (1). Em parte, em decorrência do modismo do estudo dos movimentos sociais e da suposição do primado da organização como meio de manifestação da vontade social e política das chamadas classes populares. Mas, também, em decorrência da dificuldade para tratar sociologicamente de processos sociais em conflito com o pressuposto moderno da razão. E, finalmente, em parte também, em conseqüência da discutível suposição de que os movimentos sociais constituem formas de ação coletiva mais desenvolvidas e acabadas do que as do comportamento coletivo. Não deixa de chamar a atenção do pesquisador que na Enciclopédia Internacional de Ciências Sociais o verbete comportamento coletivo tenha sido substituído por movimentos sociais (2). Outra dificuldade, certamente, é a decorrente do fenômeno em si. O linchamento, como as outras duas formas de manifestação coletiva indicadas, resulta da decisão quase sempre repentina, impensada, de motivação súbita e, de modo geral, imprevisível. Sendo legalmente modalidades de delito, os participantes 
dessas manifestações prontamente se recolhem ao anonimato. Assim como a polícia dificilmente encontra uma testemunha da ocorrência, também o pesquisador tem poucas possibilidades de localizar informantes que lhe permitam reconstituir o acontecimento com o cuidado que desejaria.

Por outro lado, a literatura sociológica disponível sobre o tema dos linchamentos é basicamente americana. As indicações existentes e o meu próprio estudo preliminar sobre o tema sugerem diferenças entre os linchamentos nos Estados Unidos e os linchamentos no Brasil. Lá, a motivação racista da violência e o problema do Sul dominaram o interesse dos estudiosos. Algo próximo dos nossos casos de linchamentos no século XIX. A relação entre linchadores e vítimas aparece claramente demarcada por uma linha de casta. Aqui, ao contrário, não se tem informação suficiente sobre distinções raciais na prática dos linchamentos. É verdade que há indícios de que o negro é vítima predileta de linchadores (3). Mas, há indícios, também, de negros participando de linchamentos de negros. Fica difícil, pois, assumir o preconceito racial como motivação fundamental dessa forma de justiçamento. É claro, e sabemos todos, que o ocultamento do preconceito e da discriminação raciais opera acentuadamente no nosso caso, introduzindo uma dificuldade adicional no estudo dessa modalidade de violência coletiva.

Os estudos americanos indicam, no entanto, aspectos do problema cuja observação pode ser pertinente no caso brasileiro. As estudos sobre o Sul dos Estados Unidos sugerem que ali os linchamentos, em sua fase mais aguda, entre 1870 e 1930, tiveram um objetivo social além daquele que poderia ser indicado como o motivo imediato da violência, que era freqüentemente o da violação da mulher branca pelo homem negro: o enquadramento da população negra nos limites de sua casta. Os brancos sentiam-se ameaçados pelos negros em duas frentes: no mercado de trabalho e no poder. As hipóteses dos sociólogos americanos tratam de dar conta dessas fontes de disputa, produzidas seja pela decadência dos agricultores brancos, empobrecidos pela perda da terra e impelidos a uma redefinição de suas relações sociais já não mais como proprietários, mas como arrendatários e parceiros, seja pela extensão de direitos políticos virtuais aos negros com o fim da escravidão e a derrota do Sul na Guerra Civil (4). Esses estudos indicam, sociologicamente, que a motivação racial para o linchamento é apenas racionalização que a sugere naquelas circunstâncias. A crise social que leva à prática do justiçamento tem uma raiz mais profunda. De um lado, manifesta-se como deterioração de uma hierarquia social pré-existente e a conseqüente redução das condições de vida de uma parcela da população (no caso, branca, proprietária e partícipe do poder) àquelas condições, tidas como atributos de categorias sociais inferiores, desprovidas de direitos sociais e políticos. De outro, manifesta-se como invasão de âmbitos e direitos por categorias sociais deles até então excluídas, como ocorre com o direito de voto aos novos cidadãos originados da abolição da escravatura nos Estados Unidos. 
Em ambos os casos, estamos diante de um processo de mudança social, de alteração na hierarquia das classes e grupos sociais, que se expressa e se torna socialmente visível pela decadência e não pela ascensão social. Ao menos, estamos diante de circunstâncias em que a incorporação à cidadania de um grupo até então dela excluído, como o dos ex-escravos, é interpretada por grupos dominantes como indicação de degradação social de todos e não como indicação de desenvolvimento social. A derrota do Sul na Guerra Civil introduziu um componente nesse processo que não pode ser subestimado. A rígida sociedade da plantation foi, na verdade, alcançada por transformações que lhe chegavam de fora para dentro. O fim da escravidão e a extensão dos direitos civis aos negros foram imposições do norte industrial e desenvolvido, o qual além do mais estava impedindo que os interesses territoriais dos grandes proprietários sulistas se estendessem às terras do oeste americano, asseguradas à ocupação da economia familiar dos agricultores de ideologia liberal. Concretamente, as transformações econômicas e sociais conduzidas pelo Norte enclausuraram o Sul, impondo idéias e instituições liberais a uma sociedade sem alternativas econômicas. Os linchamentos no Sul parecem indicar uma tentativa dos brancos, alcançados pela decadência, de preservar as linhas de casta e seus privilégios mesmo onde e quando eles já não tinham mais sentido nem viabilidade econômica, impondo predominantemente aos negros a inferioridade e a sujeição por meio do terror da violência privada.

A sociedade americana conheceu duas modalidades sociais de prática dos linchamentos: o mob lynching e o vigilantism. Nesse sentido há, também, diferenças com relação à sociedade brasileira. Os linchamentos que aqui ocorrem são predominantemente do tipo mob lynching, grupos que se organizam súbita e espontaneamente para justiçar rapidamente uma pessoa que pode ser ou não ser culpada do delito que lhe atribuem. É um tipo de justiçamento cuja lógica está subjacente ao acontecimento em si e raramente pode ser explicado de modo racional pelos participantes. Mais raro aqui, embora ocorram, são os linchamentos praticados por grupos de vigilantes. Esses grupos notabilizaram-se no Oeste americano e foram consagrados pelos filmes do gênero western.

Também no Sul dos Estados Unidos houve vigilantismo, praticado numa certa fase da história da KU KLUX KLAN. O típico vigilantismo, porém, está associado à expansão da fronteira e à ocupação do Oeste americano. Os justiçamentos nesse caso decorriam da ação de grupos organizados que impunham valores morais e normas de conduta através do julgamento rápido e sem apelação da própria comunidade. Essa forma de punição vem da tradição puritana e os estudiosos se referem a muitos casos desse tipo desde, pelo menos, o início do século XVIII. No meu modo de ver, os linchamentos praticados pelos vigilantes tinham motivação e conteúdo substancialmente diferentes dos praticados contra os negros no Sul dos Estados Unidos. Se no Sul o objetivo era o de manter a população negra nos limites de sua casta, dissuadindo-a de invocar os direitos assegurados nas leis, no 
Oeste o objetivo era o oposto: desencadear uma pedagogia da violência com o objetivo de impor o acatamento da moralidade puritana tradicional, a ordem e a lei. É verdade que em ambos os casos, o pretexto para linchar derivava de algum delito, pelo qual, no Sul, um branco não seria necessariamente linchado e, no Oeste, um respeitador da lei e da moral não o seria, a não ser por engano. Nos dois casos, a inspiração dos linchadores era conservadora e orientada para a preservação da ordem que se acreditava ameaçada. No Oeste, mais claramente, a ação dos vigilantes procurava preservar uma ordem anterior e impedir que a nova sociedade, em gestação no espaço novo da fronteira, escapasse dos valores e orientações tradicionais da sociedade. A ação dos vigilantes definia, assim, uma certa concepção do estranho e do estranhamento, do forasteiro e estrangeiro, criando um poderoso e violento mecanismo de controle social e uma pedagogia da ordem que ressocializava os adventícios e os enquadrava nos princípios da tradição puritana.

Nos dois casos, uma outra diferença com relação aos linchamentos na sociedade brasileira: na América, eram predominantemente rurais, mesmo no Oeste recém-ocupado onde o urbano mal se constituíra. No Brasil, são predominantemente urbanos, embora haja registros de linchamentos rurais e outros envolvendo membros de populações indígenas (nos quais, portanto, a motivação racial está claramente presente). Além disso, a tradição puritana ofereceu um articulado quadro de referência para a prática do justiçamento dos que se distanciavam dos valores e das normas dominantes. Com ele, os linchamentos, tanto no sul como no Oeste (como os mais antigos, no Leste), ganhavam imediatamente significação e podiam ser racionalmente explicados até pelo homem comum, pois tanto se justificavam pelo racismo quanto pela moralidade tradicional. No nosso caso, não há, ainda, um quadro de referência que permita situar e explicar imediatamente os linchamentos do período recente.

É nesse sentido que os aspectos dos linchamentos considerados secundários pelos pesquisadores americanos podem ser mais centrais e mais explicativos no caso brasileiro. Se nos Estados Unidos há claramente um caráter pedagógico na prática do linchamento, no caso brasileiro a tentativa de impor valores e normas de conduta não é evidente. Os linchamentos que aqui ocorrem, pela forma que assumem e pelo caráter ritual que parecem ter, são claramente punitivos. É claro que o eram também nos Estados Unidos. Mas, ali, os diferentes estudos mostram que os linchadores pretendiam, com sua violência, alcançar prioritariamente mais do que a própria vítima. Aqui, as indicações sugerem que os linchadores querem atingir fundamentalmente a própria vítima, não havendo nítidas preocupações com as vítimas potenciais. Provisoriamente, pode-se dizer que aqui ainda predominam fortemente os componentes irracionais do comportamento coletivo. Aqui, o objetivo não é o de prevenir o crime por meio da aterrorização, mas o de puni-lo com redobrada crueldade em relação ao delito que o motiva. Aqui, o linchamento é claramente vingativo. 
No nosso caso, os linchamentos sugerem que há um arraigado sistema de valores subjacente ao comportamento coletivo violento. E, ao mesmo tempo, uma combinação difícil entre tal sistema e os valores racionais da lei e da justiça. Há uma dupla moral envolvida nessas ocorrências - a populare a legal. Na verdade, esta última está sendo julgada por aquela. A legitimidade desta está em questão. Com seu ato, os linchadores indicam que há violações insuportáveis de normas e valores, mesmo para um delinqüente preso: no período recente há vários casos de presos que lincham companheiros de cela quando sobre eles pesa a acusação de estupro de crianças.

A questão central é esta: por que a população lincha? A partir do conhecimento que se tem de diferentes modalidades de linchamento em diferentes lugares do país, a hipótese mais provável é a de que a população lincha para punir, mas sobretudo para indicar seu desacordo com alternativas de mudança social que violam concepções, valores e normas de conduta tradicionais, relativas a uma certa concepção do humano. Uma hipótese decorrente é a de que o linchamento é uma forma incipiente de participação democrática na construção (ou reconstrução) da sociedade, de proclamação e afirmação de valores sociais, incipiente e contraditória porque afirma a soberania do povo, mas nega a racionalidade impessoal da justiça e do direito.

O linchamento não é uma manifestação de desordem, mas de questionamento da desordem. Ao mesmo tempo, é questionamento do poder e das instituições que, justamente em nome da impessoalidade da lei, deveriam assegurar a manutenção dos valores e dos códigos. Se nos Estados Unidos as elites locais, especialmente no Oeste, tomaram nas mãos a obediência à lei, através dos vigilantes, no nosso caso, as elites não têm demonstrado identificação com a justiça de rua. Ao contrário, quando participam de linchamentos, como tem acontecido nas grandes cidades do interior, fazem-no procurando ocultar sua participação, limitando-se ao caráter punitivo do seu ato. Essa ambigüidade parece indicar que a tradição política do poder pessoal, no Brasil, está em crise. Ela tem sido forte ao longo do tempo, dispensando, portanto, a prática da participação coletiva na justiça de rua, pois, para isso, as elites dispunham e dispõem de jagunços e pistoleiros.

Finalmente, no nosso caso, os linchamentos parecem estar associados à precária constituição do urbano. Nesse sentido, aparentemente combinam-se situações e motivações que tanto existiram nos mob lynching quanto na ação dos vigilantes, nos Estados Unidos. Aqui também os linchamentos se adensam nas áreas periféricas de cidades como São Paulo, Rio de Janeiro e Salvador, onde justamente se concentram os migrantes do campo, recentes ou não, privados da terra e do trabalho regular, vivendo no limite da economia estável e da sociedade organizada, como ocorria com os brancos empobrecidos no Sul dos Estados Unidos, principais envolvidos na prática de tal violência. Ao mesmo tempo, uma 
população dividida entre a desmoralização completa e a desesperada necessidade de afirmação dos valores mais tradicionais da família e da vizinhança. É nesse âmbito que a ameaça da desagregação social se torna mais visível e mais provável. É nele, também, que ganham visibilidade os prováveis agentes concretos da ruptura, do perigo e da alternativa próxima e ameaçadora que é a de vítima permanente da delinqüência ou, mesmo, a de delinqüente.

As fontes de informação para o estudo sociológico dos linchamentos são precárias, como já indiquei. Há claramente duas alternativas apontadas pela tradição dos estudos americanos e que não são diferentes entre nós. Uma é a dos estudos de caso (5). Com o tempo tal linha de investigação deveria ser estimulada para que fornecesse detalhes explicativos a respeito da inserção dessa modalidade de violência nos processos sociais mais amplos. Outra, é a da sistematização das informações disponíveis em quadros informativos amplos que permitam o estudo comparativo das ocorrências. Nesse caso, a fonte disponível é a do noticiário dos jornais. Lembro que nos Estados Unidos, a maioria dos estudos sobre linchamentos tem como fonte e base um elenco de casos ocorridos entre $1889 \mathrm{e}$ 1918 informado pelos jornais (6). A segunda orientação é indispensável para que a primeira se situe num quadro de referência que dê conta das tendências e condições do problema. Aliás, nos Estados Unidos, os estudos de caso dos linchamentos vieram na sucessão de um grande número de estudos de correlações baseadas no levantamento geral e preliminar das informações sobre o tema divulgadas pelos periódicos.

Com a pesquisa em curso, meu objetivo é produzir um elenco semelhante de casos ocorridos no Brasil. As informações publicadas pelos jornais são detalhadas e oferecem dados sociologicamente relevantes para o exame das hipóteses consideradas. O fato de que esse catálogo de casos possa ser publicado abre caminho para que outros estudos sejam desenvolvidas sobre o tema. Mas, o objetivo principal é o de realizar um estudo de causas, circunstâncias e ritos dos linchamentos no período recente. Os linchamentos criam situações que podem ser tratadas experimentalmente como tentativas de (re)invenção social, através de comparações das diferentes ocorrências. Através de seu estudo é possível sugerir alternativas de interpretação para as complicadas mudanças que estão ocorrendo na sociedade brasileira desde os anos sessenta, claramente marcadas pela desagregação social.

Meus estudos sobre linchamentos no Brasil não é pesquisa concluída, mas execução de um projeto de acompanhamento de casos desse tipo de violência. $\mathrm{O}$ já realizado levantamento de 515 casos e a definição do quadro de variáveis que o material permite formular possibilita algumas considerações sobre o tema. Possibilita, sobretudo nesta fase, considerações sobre as próprias condições de realização de um estudo sobre o assunto entre nós. 
O levantamento bibliográfico, a localização e reprodução do material só em pequena parte puderam ser feitos no Brasil, onde é escassa a literatura especializada a respeito. A maior parte do levantamento de dados foi feita na França e, sobretudo, na Inglaterra, aproveitando oportunidades de viagens do pesquisador a esses países. O exame inicial do material coletado sugeriu ser possível desdobrá-lo em número de variáveis maior do que o inicialmente previsto, ampliando as possibilidades da análise sociológica, especialmente no que se refere aos aspectos propriamente rituais e interativos do linchamento.

A principal fonte de dados para esse tipo de comportamento coletivo é o noticiário dos jornais, como já comentado, tal como se deu nos Estados Unidos. Ocorrência súbita, impensada, explosão passional determinada por fortuita combinação de circunstâncias, os linchamentos não se situam entre os acontecimentos previsíveis, que viabilizem a pesquisa sociológica planejada e a presença testemunhal do pesquisador. Mesmo que fosse possível alguma previsão, ainda assim haveria problemas adicionais. Dos 515 casos de linchamentos e tentativas de linchamento arrolados, identificados e classificados até agora, vários sugerem que, ainda que sejam iminentes as circunstâncias de sua ocorrência, o desenlace pode demorar muitas horas, muitos dias e até muitas semanas. E, muitas vezes, nem mesmo se dar. Embora o ato em si esteja marcado, aparentemente, por súbita espontaneidade, os dados sugerem que os linchamentos decorrem da combinação de dois impulsos de ritmos diferentes: a constatação e interpretação de uma violação de norma social essencial, que corresponde ao que se poderia provisoriamente entender como fase de julgamento popular do delito - o reconhecimento de que um crime grave foi cometido (a gravidade do crime, porém, nada tem a ver com a gravidade definida nas leis e códigos jurídicos). Os dados colhidos indicam que essa fase de julgamento, tanto individual quanto coletivo, pode ser rápida (coisa de minutos) ou relativamente lenta (dias, semanas), mas de qualquer modo é relativamente mais demorada do que a fase seguinte, a da aplicação da pena, do linchamento propriamente dito. Esse segundo impulso pode se desdobrar de modo incrivelmente rápido, dependendo apenas dos índices de participação e crueldade envolvidos (pode levar de cinco a vinte minutos e, excepcionalmente, mais).

A ampla literatura sociológica que pude examinar nesta fase da pesquisa, relativa sobretudo ao país que tem a mais dramática história de linchamentos, os Estados Unidos, sugere que a própria orientação interpretativa dos pesquisadores confundiu-se e dividiu-se com relação a esses dois momentos do processo. A maioria dos sociólogos, inspirados sobretudo na obra de Le Bon (7), concentrou seu interesse no segundo momento, contraditoriamente, porém, buscando causas estruturais para explicar acontecimentos não-estruturais. É o caso dos estudos que intentaram estabelecer correlações entre o preço do algodão no Sul dos Estados Unidos, a piora nas condições de vida dos agricultores brancos e pobres, a concorrência do negro no mercado de trabalho e a ocorrência de linchamentos (8). 
Essa correlação pode ser estabelecida positivamente nos casos em que a vítima é negra. Mas, deixa sem explicação o grande número de linchamentos no Oeste americano, em que as vítimas não eram negras e a motivação não era necessariamente racial (9). As mesmas causas estruturais, porém, podem provavelmente explicar vários outros fenômenos sociais, sem que se lhes possa atribuir a qualidade de causas de linchamentos. De qualquer modo, os estudos referidos, embora não o realizem de forma satisfatória, indicam haver circunstâncias imediatas, no limiar do irracional, que atuam decisivamente no comportamento dos grupos que lincham.

Nos últimos anos, surgiram novas perspectivas para o estudo dos linchamentos, elaboradas pelos historiadores, indicadas em estudos de caso e baseadas em demorados e trabalhosos registros de história oral. Nesses estudos, tem sido possível resgatar evidências de que os elementos que aparecem como causa imediata dos linchamentos já estão presentes no cotidiano das relações sociais, embora não possam ser captados através de estudos de causas propriamente estruturais desse tipo de violência. Além disso, os estudos de caso relativizam enormemente os muitos preconceitos envolvidos em apressados julgamentos expressos no noticiário dos jornais, que tem sido, em vários países, a principal fonte de dados para o estudo do problema. Os estudos retrospectivos de casos, realizados nos Estados Unidos, são igualmente indicativos das reais dificuldades para se obter informação direta, de primeira mão, de testemunhas eventuais. Meio século depois das ocorrências, as testemunhas ainda pedem o anonimato e temem ver-se expostas a represálias simplesmente pelo fato de contarem o que sabem sobre esses acontecimentos do passado. Ou seja, mantêm ainda hoje o mesmo temor que tinham quando os acontecimentos se deram.

Os estudos de caso mostram claramente que o linchamento envolve mais do que súbita e solidária decisão de matar alguém de forma violenta e coletivamente. Há uma certa idéia de corpo, de pertencimento, envolvida na ocorrência. Evidentemente, isso é mais claro nos inúmeros linchamentos ocorridos em pequenas localidades rurais, onde todos se conhecem. No caso brasileiro, em que predominam linchamentos nas grandes cidades, como São Paulo, Rio de Janeiro e Salvador, a situação de anonimato é patente em muitas das ocorrências, embora não em todas. Dificilmente, no futuro, será possível realizar estudos detalhados de caso, como está se fazendo agora nos Estados Unidos. Mas, onde os linchamentos são praticados pela ação de grupos de vizinhança, seja no interior seja nas grandes capitais, o material disponível já indica que a própria polícia tem dificuldade para obter informações que lhe permitam caracterizar o crime e indiciar participantes. Muitas vezes, os moradores silenciam até mesmo sobre a identidade do linchado, embora saibam, evidentemente, a quem lincharam e o porquê. Mesmo tendo em conta que, no Brasil, uma significativa proporção de linchamentos é praticada por grupos de vizinhança, é preciso considerar, também, que ocorrem na maior parte em bairros de concentração de migrantes, marcados por grande mobilidade. Será difícil localizar os participantes no futuro, quando determinada distância no tempo facilitar o estudo retrospectivo das ocorrências. 
Procurei testar a possibilidade de alguma previsão no comportamento de possíveis grupos de linchadores, anotando e acompanhando casos que, no noticiário da imprensa, se desenhavam nitidamente com os mesmos contornos e possíveis motivações de ocorrências delituosas que culminaram em linchamentos. $\mathrm{Na}$ maioria dos casos que acompanhei, o desenlace não foi o linchamento nem mesmo a tentativa de linchamento. O que torna praticamente inútil o uso desse recurso para identificação de possíveis ocorrências e eventualmente a realização de um trabalho documental diverso do que se pode fazer através do noticiário de jornais. De qualquer modo, haveria aí sempre um problema ético, sobretudo para o pesquisador: diante da previsibilidade de um linchamento, seria lícito não agir para preveni-lo ao invés de simplesmente agir para documentá-lo?

O uso do material jornalístico no estudo sociológico de linchamentos, nos Estados Unidos, teve dois momentos distintos. Nos estudos iniciais, mais antigos, foi utilizado material colhido diretamente pelos pesquisadores, ao acaso de circunstâncias e possibilidades. Num segundo momento, os dados foram retrospectivamente colhidos e classificados sistematicamente por institutos de pesquisa, interessados sobretudo em caracterizar o racismo que estava na raiz das motivações para linchar. O material dessas fontes, de qualquer modo coletado em jornais, passou a ser e é até hoje a base principal de realização de estudos sociológicos e históricos sobre o problema. No Brasil, o jornal é a única fonte sistemática e, ainda assim, limitada pela casualidade do acesso do pesquisador a publicações que tenham notícias sobre o assunto. Além disso, ocasional e excepcionalmente, amigos me remetem recortes de diferentes regiões do Brasil (10). Porém, de modo algum é possível, por enquanto, mesmo com recursos, ainda que modestos, obter um levantamento razoavelmente completo de ocorrências em todo o país, sobretudo em pequenas localidades de regiões remotas onde linchamentos estão acontecendo, mas cujas notícias jamais chegam aos jornais (11). É desejável, porém, que se tenha aqui, no futuro, séries históricas, como as que foram produzidas nos Estados Unidos, mediante pesquisa em centenas de jornais de todo o país.

De qualquer modo, o arquivo que organizei até agora é, provavelmente, o mais completo e criterioso com relação ao Brasil. Embora haja as limitações indicadas quanto à representatividade estatística dos casos noticiados, o material colhido é rico de informações e detalhes sociologicamente relevantes. Consegui distribuir as informações jornalísticas por 72 variáveis, o que permite testar e analisar um grande número de associações de dados e verificar características e regularidades essenciais para o estudo sociológico do problema. Esse detalhamento não foi feito nos estudos americanos, limitados, no geral, a indagações sobre as possíveis grandes causas dos linchamentos e, portanto, a meia dúzia de variáveis. Mesmo assim, não se trata de número que possa ser considerado amostra de algum modo probabilisticamente representativa do universo de linchamentos no país. Algumas indicações relativas ao estado da Bahia são reveladoras das limitações que, nesse particular, têm os dados colhidos em jornais. 
A própria imprensa difundiu, em diferentes ocasiões, a propósito de novos linchamentos naquele estado, informações liberadas pela Polícia quanto a números oficiais dessas ocorrências, durante determinado período até aquele momento.

O quadro é o seguinte:

Tabela 1

Linchamentos no estado da Bahia

$(1988 / 1991)$

\begin{tabular}{|cccc|}
\hline & $\begin{array}{c}(\mathrm{A}) \\
\text { Linchamentos } \\
\text { Ano }\end{array}$ & $\begin{array}{c}\text { Linchamentos } \\
\text { ocorridos }\end{array}$ & \% B /A \\
\hline 1988 & 105 & 5 & 4.8 \\
1989 & 103 & 12 & 11.7 \\
1990 & 105 & 36 & 34.3 \\
1991 & 79 & 27 & 34.2 \\
\hline
\end{tabular}

Mesmo que aleatoriamente, pode-se projetar esses índices para o conjunto do país e presumir que os dados registrados pela imprensa, na melhor das hipóteses, correspondem a cerca de um terço do total de ocorrências. O próprio quadro indica, porém, que a atenção dos jornais pelos casos de linchamento cresceu paulatinamente e só chegou a um terço das ocorrências quando se tomou consciência de que era alto o seu número. $\mathrm{O}$ mesmo não aconteceu em outros estados. Em São Paulo, em diversas ocasiões, linchamentos ou tentativas de linchamento divulgados pela televisão não foram noticiados pelos jornais. O que sugere que além de interesse limitado por esse tipo de comportamento coletivo, os jornais devem ter noticiado seletivamente as ocorrências. Nos Estados Unidos, estudos sobre o problema demonstraram que os linchamentos chegavam aos grandes jornais apenas quando havia na localidade algum correspondente das grandes agências noticiosas (12). Para o caso brasileiro, se tomarmos como referência os dois jornais até agora mais representados neste levantamento ( $O$ Estado de S. Paulo e Folha de S. Paulo), veremos que os mesmos têm correspondentes apenas em capitais e cidades principais do próprio estado de São Paulo. Provavelmente, linchamentos ocorridos em regiões interioranas e mesmo rurais sequer chegaram ao conhecimento dos correspondentes, fazendo supor que foram noticiados predominantemente determinados tipos de linchamentos, de característica mais claramente urbana, e menos os propriamente rurais. 
Com relação aos casos americanos, há diferenças na documentação. Foi macabro traço dos linchamentos, sobretudo no Sul dos Estados Unidos, fotografar o cadáver do linchado, ainda dependurado numa árvore ou num poste, para venda e exibição da fotografia a curiosos e participantes (sem contar a distribuição de pedaços do cadáver, como orelhas e dedos, a título de lembrança e, provavelmente, prova de participação no ato punitivo). Talvez porque aqueles tenham sido predominantemente linchamentos comunitários, praticados por populações que haviam incorporado a fotografia como um documento corriqueiro da crônica local. Esse procedimento não acontece com as populações das localidades brasileiras nas quais tem ocorrido esse tipo de violência. Houve, entretanto, a conhecida exceção quanto ao vídeo feito por um amador, em Matupá (Mato Grosso), com o objetivo de vendê-lo a algum canal de televisão, e que registrou o momento em que três assaltantes foram queimados vivos pela multidão. Paralelamente a isso, porém, a própria televisão tem transmitido, ao vivo, tentativas de linchamento e até os próprios linchamentos, como ocorreu há pouco no interior do Paraná, quando, entre outros, um médico e um policial foram linchados. Isso traz um novo tipo de documento ao estudo, que não houve no caso dos estudos americanos. Sobretudo importante, porque permite obter-se evidências visuais muito expressivas tanto da ocorrência quanto do comportamento dos participantes. Essas evidências são principalmente importantes no exame dos aspectos propriamente rituais dos linchamentos.

O propósito de dar destaque à dimensão ritual dos linchamentos é exeqüível sobretudo porque os jornais, com grande freqüência, se interessam pelos detalhes da execução violenta, que são, na verdade, indicadores de ritos sacrificiais. Os 515 casos já arquivados e analisados, monstram que as notícias de periódicos oferecem consistentes informações, sem que o redator saiba, às vezes minuciosas, sobre os aspectos propriamente rituais dos linchamentos. O redator propõe-se apenas a noticiar uma ocorrência anormal e chocante, dando dela os detalhes que lhe chegam às mãos. Não sabe, porém, nem tem a intenção de fazê-lo, que está relatando detalhes de um rito sacrificial de raiz ancestral, o qual expressa processos de desagregação social, de precária constituição do urbano e proclamação de uma concepção de vida conservadora e pré-urbana. Nada deve ser filtrado neste uso da notícia de jornal, para que se possa ter uma rica compreensão sociológica dessas ocorrências, isto é, de seus significados - não só os imediatos (que são os que norteiam a construção da notícia), mas também os mais profundos e ocultos (os que a explicam). O que importa, nessa orientação teórica, não é a linha, mas a entrelinha. A objetividade não é a da construção do dado, que está fora do alcance e da intervenção do pesquisador, como ocorre no caso dos documentos históricos, mas do sociólogo que os lê, situa e interpreta.

$\mathrm{O}$ arrolamento feito até agora indica com clareza que a ocorrência de um simples linchamento numa localidade rompe certos constrangimentos sociais à 
prática da violência direta: em muitos lugares, um primeiro linchamento é, com facilidade, seguido de outros, ainda que com o passar do tempo (13). É o que abre caminho para a eficácia do imaginário arcaico na ação do homem comum e sua explosão intensa na rotina cotidiana da população. Portanto, está indicado aí o que interessa: alterações na orientação da mudança social, de valores, normas e padrões de comportamento e, sobretudo, padrões de interação.

Esses aspectos rituais, aliás, têm sido analisados, no caso americano, muito mais por estudiosos da literatura, já que é na ficção que se tem captado e registrado os aspectos dramáticos e simbólicos da violência racial que se consuma através dos linchamentos. É significativo que esses aspectos estejam ausentes da literatura sociológica. Talvez, justamente, porque ela ficou muito dependente dos aspectos exteriores e formais do noticiário de jornal, mas também porque se interessou quase exclusivamente pelos que se envolvem na ação de linchamento e não pelas vítimas de tal violência.

O material já coletado, relativo aos 515 linchamentos e tentativas de linchamento para o período de 1970 a 1994, envolve um total de 739 vítimas (366 foram mortas, 69 feridas, 233 salvas, 50 escaparam e não há informações para 21 delas). Esses linchamentos e tentativas estão assim distribuídos por regiões e períodos:

Tabela 2

Brasil - Linchamentos

por período e por região, 1970-1994

(Em \%)

\begin{tabular}{|lcc|}
\hline Região & Até 1984 & Após 1984 \\
\hline Norte & 7.8 & 8.3 \\
Nordeste & 6.4 & 34.2 \\
Sudeste & 82.3 & 48.2 \\
Sul & 2.1 & 4.5 \\
Centro-oeste & 1.4 & 4.8 \\
$($ N=100\%) & $(141)$ & $(374)$ \\
\hline
\end{tabular}

O principal, porém, é ter podido organizar um extenso formulário e classificar os diferentes aspectos de cada caso, de modo a analisar associações minuciosas entre eles. Embora o levantamento realizado não possibilite fazer previsões probabilísticas, permite analisar com riqueza de detalhes as associações de traços, características e componentes dos casos arrolados. A consistência qualitativa dos dados é animadora e certamente abre amplas possibilidades de acompanhamento dos desdobramentos da prática do linchamento no Brasil. 
Ao mesmo tempo, como já mencionei, encontrei severas dificuldades para localizar, no Brasil, uma significativa bibliografia de comparação relativa a outros países, e, mesmo a orientações teóricas no estudo do problema. Aproveitei duas viagens ao exterior para realizar demorado e completo levantamento bibliográfico, primeiramente, na Maison des Sciences de l'Homme, em Paris. A partir de referências indiretas contidas em estudos sobre outros temas e de indicações em diferentes indexadores, consegui organizar, no Brasil, uma listagem inicial de textos. Desses, aqui encontrei menos de 10\% dos listados. Em Paris, localizei outros $20 \%$. Finalmente, em uma estada mais demorada na Universidade de Cambridge (Inglaterra) ampliei consideravelmente essa lista, localizando os demais 70\% dos textos arrolados, num total de noventa e seis artigos e livros (14). Esse material já foi todo lido, analisado e corresponde à maior parte da bibliografia já produzida sobre o tema.

Defini e calculei índices de participação e de atrocidade nos linchamentos para número expressivo de ocorrências. Houve possibilidade de calcular os dois índices, nos mesmos casos, para um número que ultrapassa consideravelmente o de casos em que se pôde fazer cálculos similares nos linchamentos americanos. Nos Estados Unidos foi possível fazê-lo para 60 linchamentos, ocorridos no período de 1899 a 1946 (15). Na minha pesquisa, até agora, foram calculados índices para 138 casos acontecidos entre 1970 e 1994, mais do que o dobro dos americanos. Essa disparidade se explica pela limitação do número de variáveis consideradas quando se produziu o levantamento básico de notícias de jornais até hoje utilizado pela maioria dos estudiosos do tema nos Estados Unidos. Esses índices são importantes para determinar alterações nos aspectos qualitativos da prática de linchamento. O índice de atrocidade, tendo como ponto mediano 0.25 (numa escala de zero a cinco), sugere equilibrada distribuição dos casos em $49.6 \%$ de baixa atrocidade e $50.4 \%$ de alta atrocidade. Agrupei os casos em dois períodos: até 1984 (29.6\%) e a partir de 1985 (70.4\%). As mudanças de orientação das multidões têm sido pequenas e comparativamente também pequenas as variações em diversas situações.

Tabela 3

Atrocidade nos linchamentos no Brasil, conforme a região $(\mathrm{Em} \%)$

\begin{tabular}{|lcc|}
\hline Região & Baixa atrocidade & Alta atrocidade \\
\hline Norte & 10.1 & 8.6 \\
Nordeste & 30.9 & 31.4 \\
Sudeste & 56.1 & 49.3 \\
Sul & 0.7 & 8.6 \\
Centro-oeste & 2.2 & 2.1 \\
Total $(\mathrm{N}=100 \%)$ & $(139)$ & $(140)$ \\
\hline
\end{tabular}

Obs.: Os 279 casos correspondem àqueles em relação aos quais foi possível calcular o índice de atrocidade. 
Tabela 4

Brasil - Distribuição dos índices de participação, conforme o motivo do linchamento outentativa de linchamento (Em \%)

\begin{tabular}{|lcc|}
\hline \multicolumn{1}{|c}{ Motivo } & Alta & Baixa \\
\hline & 6.7 & 12.3 \\
Fútil & 57.9 & 34.0 \\
Crime contra a pessoa & 22.0 & 11.3 \\
Crime contra a pessoa e a propriedade & 23.4 & 38.6 \\
Crime contra a propriedade & - & 3.8 \\
Sem indicação & $(164)$ & $(106)$ \\
Total (N=100 \%) & & \\
\hline
\end{tabular}

Os linchamentos são mais do que um problema social; são expressões dramáticas de complicados processos de desagregação social e, também, de busca de um padrão de sociabilidade diferente daquele que se anuncia através das tendências desagregadoras. Seria pobre a interpretação que se limitasse a vê-los como manifestação de conservadorismo ou, ao contrário, a neles ver indicação de uma conduta cidadã e inovadora; antes, é necessário neles resgatar a dimensão propriamente dramática do medo e da busca, ingredientes que muitas vezes acompanham os processos de mudança social.

O tema do linchamento é um desses temas reveladores da realidade mais profunda de uma sociedade, de seus nexos mais ocultos e ativos. Nos linchamentos se faz presente a dimensão mais oculta do nosso imaginário, sobretudo nas formas elaboradas e cruéis de execução das vítimas. A centralidade do corpo nesse imaginário explode nas ações de linchamento, quando pacíficos transeuntes, pacíficos vizinhos, devotados parentes e pais se envolvem na execução de alguém, a quem, às vezes, estão ligados por vínculos de sangue, às vezes o próprio filho. $\mathrm{E}$, sobretudo, quando se envolvem na mutilação, na castração e na queima da vítima ainda viva. A forma que entre nós assume a chamada justiça popular está muito distante do romantismo ingênuo que tem marcado tão fundo estudos sobre a cultura popular em nosso país e o discurso abstrato sobre a cidadania.

\section{Notas}

I Sobre linchamentos no Brasil, cf. Maria Victoria Benevides, Linchamentos: violência e justiça popular, In: Roberto Da Matta et alii, Violência brasileira, São Paulo, Brasiliense, 
1982, p. 93-101; José de Souza Martins, Linchamentos: a vida por um fio. In: Travessia, ano II, n. 4, p. 21-27. São Paulo, Centro de Estudos Migratórios, maio-ago. 1989. Em Menandro \& Souza há um bom levantamento comentado da modesta bibliografia brasileira sobre o tema, caracterizada pelo predomínio de comentários jornalísticos (ainda que escritos por cientistas sociais) e reduzido número de textos baseados em pesquisa e arrolamento de dados. Cf. Paulo Rogério M. Menandro \& Lídio de Souza, Linchamentos no Brasil: a justiça que não tarda, mas falha. Vitória (ES), Fundação Ceciliano Abel de Almeida, 1991.

2 Cf. Joseph R. Gusfield, The study of social movements. In: David C. Sills (ed.), International encyclopedia of the social sciences, v. 14, s.l., The MacMillan Company \& The Free Press, 1968, p. 445-452. Em 1961, num conhecido ensaio de Blumer, os movimentos sociais apareciam como um subcampo no estudo do comportamento coletivo. Cf. Herbert Blumer, Comportamento coletivo. In: Alfred McClung Lee (ed.), Principios de sociologia, trad. Francisco M. D. Leão et alii, São Paulo, Editora Herder, 1962, p. 207-272.

3 São escassíssimos os dados sobre a cor das vítimas de linchamentos e tentativas de linchamento no material que examinei. Esses dados apenas permitem supor que, nas ocorrências, há predomínio de negros com relação a brancos. Menandro \& Souza, porém, embora enfrentando a mesma carência de dados, conseguiram quantificar alguns casos e indicar que, para uma população negra de 5.9\%, 39.6\% das vítimas de linchamento eram negras. Cf. Paulo Rogério M. Menandro \& Lídio de Souza, ob. cit., p. 112-113. Há, contudo, problema com essa comparação, pois os autores estão considerando linchamentos ocorridos ao longo de largo período de tempo e os dados sobre a população negra do Brasil referem-se unicamente ao ano de 1980.

4 Cf. Jay Corzine, Lin Huff-Corzine \& James C. Creech, The tenant labor market and lynching in the south: a test of split labor market theory. In: Sociological inquiry, v. 58, n. 3, p. 261-278, Summer 1988; Stewart E. Tolnay; E. M. Beck \& James L. Massey, Black lynchings: the power threat hypothesis revisited. In: Social forces, v. 67, n. 3, p. 605-640, march 1989; E. M. Beck \& Stewart E. Tolnay, The killing fields of the deep south: the market for cotton and the lynching of blacks, 1882-1930. In: American Sociological Review, v. 55, n. 4, p. 526-539, Aug. 1990.

5 O livro de Rodolpho Telarolli, Poder local na República Velba, São Paulo, Cia. Editora Nacional, 1977, contém abundantes informações sobre um caso de duplo linchamento no interior de São Paulo, no século xix. De certo modo, é quase um estudo de caso sobre linchamento, mais do que um estudo sobre o poder local. É um trabalho que mostra claramente a viabilidade de detalhados estudos de caso sobre esse tipo de violência no Brasil do passado.

6 Os poucos casos de estudos brasileiros sobre linchamentos, baseados em pesquisas empíricas, também se apóiam em notícias publicadas pelos jornais. Cf. Paulo Rogério M. Menandro \& Lídio de Souza, ob. cit., passim.

7 Cf. Gustave Le Bon, The crowd: a study of the popular mind. Harmondsworth, Penguin Books, 1977.

8 Entre outros, sobre o tema, cf. E. M. Beck \& Steward E. Tolnay, The killing fields of the deep South: the market for cotton and the lynching of blacks, 1882-1930, cit. 
9 Sobre a raça das vítimas de linchamento e a distribuição das ocorrências por estado, cf. James Elbert Cutler, Linch-law: an investigation into the history of lynching in the United States. New Jersey, Patterson Smith, Montclair, 1969. Hugh Davis Graham \& Ted Robert Gurr (eds.), The history of violence in America, New York, Frederick A. Praeger, Publishers, 1969.

10 As notícias sobre linchamentos utilizadas para compor o arquivo desta pesquisa procedem aleatoriamente dos seguintes jornais e revistas: A Província do Pará (Belém, PA); A Tarde (Salvador, BA); Correio da Babia (Salvador, BA); Diário do Grande $A B C$ (Santo. André, SP); Diário Popular (São Paulo, SP); Folha de S. Paulo (São Paulo, SP); Folha da Tarde (São Paulo, SP); Isto É/Senhor; Jornal da Bahia (Salvador, BA); Jornal do Brasil (Rio de Janeiro, RJ); Jornal da Tarde (São Paulo, SP); Noticias Populares (São Paulo, SP); O Estadão (Porto Velho, RO); O Estado de S. Paulo (São Paulo, SP); O Globo (Rio de Janeiro, RJ); O Imparcial (Belém, PA); O Liberal (Belém, PA); Tribuna da Babia (Salvador, BA); Veja.

11 Em São Félix do Araguaia (MT) ocorreram pelo menos dois linchamentos, mas nenhum deles foi noticiado como tal nos jornais a que tive acesso.

12 Cf. David Snyder \& William R. Kelly, Conflict intensity, media sensitivity and the validity of newspaper data. In: American Sociological Review, v. 42, n. 1, Feb. 1977.

13 Cf. José de Souza Martins, loc. cit., p. 24-25.

14 Esses textos foram localizados principalmente na University Library, na biblioteca do Institute of Criminology e na Seeley Historical Library.

15 Cf. Brian Mullen, Atrocity as a function of lynch-mob composition: a self-attention perspective. In: Personality and Social Psychology Bulletin, v. 12, n. 2, p. 191, June 1986.

José de Souza Martins, sociólogo, é professor de Sociologia da Vida Cotidiana no Departamento de Sociologia da FFLCH-USP, fellow de Trinity Hall e professor titular da Cátedra Simón Bolivar (1993/94) da Universidade de Cambridge. 